\title{
UV-Cured Transparent Silicone Materials with High Tensile Strength Prepared from Hyperbranched Silicon-Containing Polymers and Polyurethane-Acrylates
}

Xiaojiao Jiao, Jiangling Liu, Jing Jin, Fei Cheng, Yunxin Fan, Lu Zhang, Guoqiao Lai,* Xilin Hua, and Xiongfa Yang*

Cite This: ACS Omega 2021, 6, 2890-2898

Read Online

ABSTRACT: Flexibility and mechanical performance are essential for transparent silicone materials applied in some optical and electronic devices; however, the tensile strength of transparent silicone materials is fairly low. To overcome this problem, a kind of UV-cured transparent flexible silicone material with quite a high tensile strength and elongation at break was developed through UV-initiated thiolene reaction by hyperbranched silicon-containing polymers (HBPs) with a thiol substitute and acrylate-terminated polyurethanes. Unexpectedly, it is found that both the tensile strength and elongation at break of the transparent silicone materials are extraordinarily high, which can reach $3.40 \mathrm{MPa}$ and $270.0 \%$, respectively. The UV-cured materials have good UV resistance ability because their transmittance is still as high as $93.4 \%(800 \mathrm{~nm})$ even when aged for $40 \mathrm{~min}$ in a UV chamber of $10.6 \mathrm{~mW} \mathrm{~cm} \mathrm{~cm}^{-2}$. They exhibit outstanding adhesion to substrates, and the adhesion to a glass slide, wood, and a tin plate is grade 1 . The promising results

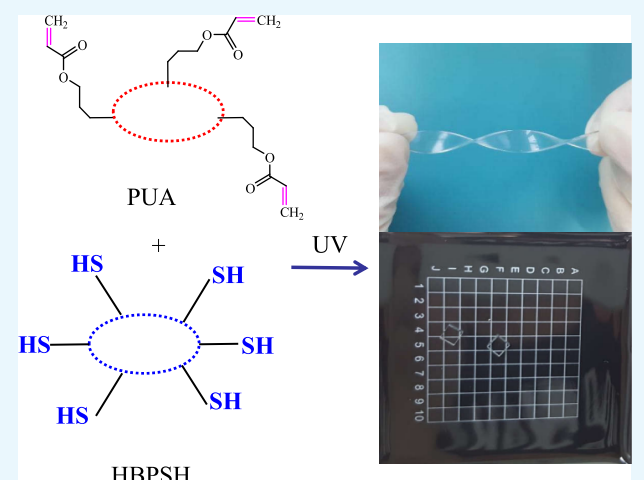
encourage us to further improve the mechanical performance of flexible transparent

HBPSH silicone materials by effective chemical modification strategies with HBPs. An attempt was made to apply the UV-cured materials in a Gel-Pak box and it could be proved that the UV-cured materials may be one of the good candidates for use as packaging or protecting materials of optical or electronics devices such as the Gel-Pak product.

\section{INTRODUCTION}

Flexibility and mechanical performance are essential for transparent polymer materials having promising applications in some optical and electronic device packaging or protecting. ${ }^{1-4}$ Transparent silicone elastomers are important candidates in optical and electronics fields by virtue of their conspicuous properties such as UV resistance ability, a wide range of service temperatures, electrical insulating property, and so on. ${ }^{5-10}$ Despite these merits for transparent silicone materials, the tensile strength of unreinforced pure silicone materials is not higher than $0.4 \mathrm{MPa}^{1{ }^{1-13}}$ Although commercial silicone elastomers Sylgard 184 and 186 and their blends have superior tensile strength than unreinforced pure silicone materials, their tensile strength is still no more than $2.4 \mathrm{MPa}^{3,10}$ The tensile strength of silicone materials can be obviously improved by adding various inorganic fillers such as nano- $\mathrm{SiO}_{2}{ }^{14}$ and carbon nanotubes; ${ }^{15}$ unfortunately, the transmittance of these silicone composites generally is too low to meet the requirements of optical devices. ${ }^{13}$ Since optical transmittance is vastly sought-after for optical devices, 3,13 effective chemical modification strategies have been developed to enhance the mechanical properties of transparent silicone materials. $^{13,16,17}$
As we know, polyurethanes (PUs) are one of the highquality elastomers due to their excellent performance such as excellent physical, chemical, and mechanical properties. ${ }^{18-21}$ Kim and co-workers prepared a series of polydimethylsiloxane-PU elastomers with a tensile strength of $6.75-10.22 \mathrm{MPa}$ and an elongation at break of $23.2-50.2 \% .^{22}$ Kozakiewicz developed moisture-cured polysiloxane urethane elastomers with a tensile strength $4.0-17.4 \mathrm{MPa}$ and an elongation at break of $340-740 \% .^{23}$ These materials have a fairly high tensile strength, but their transmittance $(400-800 \mathrm{~nm})$ is quite low, making it difficult to apply them in optical devices. Cheng et al. reported that the tensile strength of cured films from UVcurable polyether-modified polysiloxane polyurethane acrylate (PUAs) can reach $2.0 \pm 0.3-19.8 \pm 2.2 \mathrm{MPa}$, the elongation at break was in the range of $3.8 \pm 0.3-92.2 \pm 10.2 \%$, and transmittance was as high as $80 \%(400-800 \mathrm{~nm}) .{ }^{17}$ Recently, a

Received: October 27, 2020

Accepted: January 6, 2021

Published: January 22, 2021 
Table 1. Influence of Various PUAs on the Performances of Coatings ${ }^{a}$

\begin{tabular}{ccccccc} 
entry & PUAs & molar ratio of TMP to PTMG & degree of curing content/\% & pencil hardness & surface water contact angle/deg & water absorption/\% \\
\hline 1 & PUA-1 & $5: 100$ & 91.3 & $4 \mathrm{H}$ & $7 \mathrm{H}$ & 0.9 \\
2 & PUA-2 & $10: 100$ & 93.6 & $8 \mathrm{H}$ & 0.8 \\
3 & PUA-3 & $15: 100$ & 92.2 & $9 \mathrm{H}$ & 100.8 \\
4 & PUA-4 & $20: 100$ & 98.2 & $9 \mathrm{H}$ & 0.4 \\
5 & PUA-5 & $25: 100$ & 98.9 & 0.5 & 105.1 \\
\hline
\end{tabular}

${ }^{a}$ Conditions: the materials were cured for $50 \mathrm{~s}$. The molar ratio of acrylate to mercaptopropyl is $1: 2$.

kind of PU-modified material reported by Liu et al. has also displayed excellent mechanical properties. ${ }^{24,25}$ These interesting studies urge us to develop transparent silicone materials with good flexibility and mechanical performance by introduction of flexible PU segments into the main or side chain of the silicone materials.

As one of the most important hyperbranched polymers (HBPs), silicon-containing HBPs have attracted specific interest due to their potential as silicon carbide ceramic precursors, optical materials, modifiers of composites, and so on. ${ }^{26}$ Transparent silicone elastomers with a tensile strength as high as $2.4 \mathrm{MPa}$ were developed with hyperbranched polycarbosiloxanes and thiol silicone resins by our group recently, ${ }^{13}$ which induced us to try to further improve the tensile strength and elongation at break of transparent flexible silicone materials by chemical modification strategies with silicon-containing HBPs.

Apart from the relatively low tensile strength mentioned above, most of the transparent silicone materials should be cured either at an elevated temperature by hydrosilylation or by humidity for quite a long time through condensation reaction, which is usually energy-intensive, time-consuming, and not suitable for heat-sensitive or dimensional stability requirement devices. ${ }^{27}$ The UV curing method has been widely used in electronics, coatings, printing inks, and adhesives for its extensive merits over the traditional curing method including more energy conservation, higher efficiency at ambient temperature, being environmentally friendly, and being economical. $^{28-35}$

To overcome the problems discussed above, a kind of UVcured transparent flexible silicone materials with quite a high tensile strength and elongation at break were developed through UV-initiated thiol-ene reaction by hyperbranched silicone polymer with thiol substitute (HBPSH) and PUAs. The features of fabrication and performance of the UV-cured materials including tensile strength, transmittance, thermal stability, UV resistance ability, and adhesion properties to various substrates were discussed in detail. An attempt was made to apply UV-cured materials in a Gel-Pak box and it could be proved that the UV-cured materials may be one of the good candidates for use as packaging or protecting materials of optical or electronics devices such as a Gel-Pak product. The promising results of this work can encourage scientists to further improve the mechanical performance of flexible transparent silicone materials by effective chemical modification strategies with HBPs and expand the application of flexible transparent silicone materials in optical and electronic devices.

\section{RESULTS AND DISCUSSION}

2.1. Fabrication of UV-Cured Flexible Transparent Silicone Materials. 2.1.1. Influence of Various PUAs on the UV-Cured Silicone Materials. As can be seen from Table S1 and Scheme S1, the chemical structure of PUAs and the cross- linking density of the materials will be greatly affected by the molar ratio of 1,1,1-tris(hydroxymethyl)propane (TMP) to polytetramethylene ether glycol (PTMG). Therefore, various PUAs prepared with different amounts of TMP will affect the performance of the UV-cured materials obtained. It is clearly indicated in Table 1 that with the increment of TMP in PUAs, the degree of the curing content of these materials increased from 91.3 to $98.9 \%$ and the pencil hardness increased from $4 \mathrm{H}$ to even higher than $9 \mathrm{H}$. As we know, coatings are mostly used for substrate protection, so they must exhibit fairly high hardness to resist a scratch. ${ }^{36}$ The fairly high pencil hardness $(4 \mathrm{H}-9 \mathrm{H})$ will ensure the good scratch-resistant performance of the UV-cured coatings obtained. ${ }^{28}$ Previous studies reveal that the hardness of coatings mostly relies on the chemical skeleton of the polymer and the cross-linking density of the polymer network. ${ }^{37,38}$ To evaluate the cross-linking density of the UV-cured materials, a swelling experiment was carried out as shown in Table S2. It can be seen that the swelling degree (SD) of the UV-cured materials decreased steadily with increasing molar ratio of TMP to PTMG when the molar ratio of TMP to PTMG is in the range of 5:100-20:10. Therefore, the steady increment of pencil hardness of the UV-cured materials may be due to the increasing cross-linking density with the increasing TMP content of the PUAs. ${ }^{39}$

It also can be seen that the surface water contact angle of these materials is $99.0-105.1^{\circ}$, which may be ascribed to the hydrophobicity of the HBP. The water absorption of these UVcured materials is as low as $0.5-0.9 \%$, which may illustrate that the UV-cured materials have a fairly good water resistance performance.

2.1.2. Influence of Curing Time on the UV-Cured Silicone Materials. UV curing time has a very important impact on the performance of UV-cured materials, in order to determine the effect of which the UV-cured systems were cured for different times and the results are summarized in Table 2 . It can be observed clearly from Table 2 that the coatings have an advantage of high pencil hardness. The pencil hardness of the coatings can reach $5 \mathrm{H}$ and the degree of curing content can reach $84.7 \%$, respectively, even when the curing time is only 20 $\mathrm{s}$, which implies that the coatings can be cured very quickly.

Table 2. Influence of Curing Time ${ }^{a}$

$\begin{array}{cccccc}\text { entry } & \begin{array}{c}\text { degree of } \\ \text { time/s }\end{array} & \begin{array}{c}\text { surface water } \\ \text { curing } \\ \text { content/\% }\end{array} & \begin{array}{c}\text { pencil } \\ \text { hardness }\end{array} & \begin{array}{c}\text { contact } \\ \text { angle/deg }\end{array} & \begin{array}{c}\text { water } \\ \text { absorption/\% }\end{array} \\ 1 & 20 & 84.7 & 5 \mathrm{H} & 99.7 & 0.6 \\ 2 & 30 & 88.6 & 8 \mathrm{H} & 100.9 & 0.3 \\ 3 & 40 & 92.5 & 9 \mathrm{H} & 102.8 & 0.4 \\ 4 & 50 & 96.5 & 9 \mathrm{H} & 104.4 & 0.5 \\ 5 & 60 & 96.8 & 9 \mathrm{H} & 104.9 & 0.8\end{array}$

${ }^{a}$ Conditions: PUA is PUA-4. Molar ratio of acrylate to mercaptopropyl is $1: 2$. 
The pencil hardness is as high as $9 \mathrm{H}$ when the coating was cured for $40 \mathrm{~s}$ and the pencil hardness can be even higher than $9 \mathrm{H}$ if the curing time is longer than $50 \mathrm{~s}$. As reported previously, the pencil hardness of the UV-cured PUs coatings is generally in the range of $2 \mathrm{~B}$ and $\mathrm{HB}$ and not more than $2 \mathrm{H}$; therefore, these UV-cured PUs are at great risk of being scratched during the course of storage and transportation. ${ }^{28,40,41}$ Not long ago, a kind of UV-cured transparent coatings were prepared with the thiol silicone resin and PUA through a thiol-ene click reaction by our group, the pencil hardness of which was in the range of $6 \mathrm{~B}-9 \mathrm{H} .{ }^{28}$ Compared with those coatings reported previously, the transparent coatings prepared here exhibit a much higher pencil hardness, which will reduce the risk of being scratched.

It also can be observed that the degree of curing content increased continuously from 84.7 to $96.5 \%$ when the curing time increased from 20 to $50 \mathrm{~s}$, whereas if the curing time was longer than $60 \mathrm{~s}$, the variation of UV time will scarcely have an effect on the degree of curing content, which denotes that the coatings were cured completely by the UV-initiated thiol-ene reaction only for $50 \mathrm{~s}$. To seek the optimum UV-cured time, the FT-IR spectra of the coatings cured for various times, $\mathrm{HBPSH}$ and PUA were carried out as shown by Figure 1. The

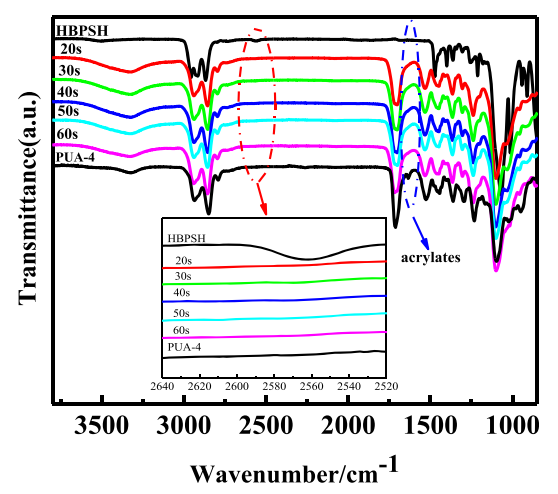

Figure 1. FT-IR spectra of HBPSH, PUA-4, and the coatings cured for various times.

characteristic peaks at $2570 \mathrm{~cm}^{-1}$ for mercaptopropyl groups, characteristic absorption at 1635 and $813 \mathrm{~cm}^{-1}$ for $\mathrm{C}=\mathrm{C}$ and $=\mathrm{C}-\mathrm{H}$ of acrylates were very weak even when the coating was only cured for $20 \mathrm{~s}$. When the UV-cured time is $50 \mathrm{~s}$, the characteristic peaks for mercaptopropyl groups and acrylate groups vanished completely. It further proved that the coating can be cured completely for $50 \mathrm{~s}$.

2.1.3. Influence of Molar Ratio of Acrylate to Mercaptopropyl on the UV-Cured Silicone Materials. The effect of molar ratio of acrylate to mercaptopropyl is revealed by Table 3. When the molar ratio of acrylate to mercaptopropyl increases from 0.8 to 2.0 , the degree of curing content increases from 74.8 to $97.3 \%$, the pencil hardness of the UVcured materials increases from $4 \mathrm{~B}$ to higher than $9 \mathrm{H}$, while water absorption decreases from 2.8 to $0.8 \%$, and surface water contact angle slightly changes from 99.1 to $108.2^{\circ}$ (Figure S5). A higher molar ratio of acrylate to mercaptopropyl scarcely has an effect on the performance of the UV-cured materials, which is quite similar to the results reported. ${ }^{28}$

2.2. Performance of UV-Cured Materials. 2.2.1. Transmittance. As we know, optical transmittance is extensively sought, especially for optics and "invisible" wearable sensors. The transmittance of the UV-cured materials obtained with
Table 3. Influence of Molar Ratio of Acrylate to Mercaptopropyl $^{a}$

$\begin{array}{cccccc}\text { entry } & \begin{array}{c}\text { molar ratio of } \\ \text { acrylate to } \\ \text { mercaptopropyl }\end{array} & \begin{array}{c}\text { degree of } \\ \text { curing } \\ \text { content/\% }\end{array} & \begin{array}{c}\text { pencil } \\ \text { hardness } \\ \text { water } \\ \text { contact } \\ \text { angle/deg }\end{array} & \begin{array}{c}\text { water } \\ \text { absorption/\% }\end{array} \\ 1 & 0.8 & 74.8 & 4 \mathrm{~B} & 99.1 & 2.8 \\ 2 & 1.0 & 82.1 & 2 \mathrm{~B} & 98.9 & 1.0 \\ 3 & 1.5 & 87.3 & 7 \mathrm{H} & 100.7 & 0.9 \\ 4 & 2.0 & 97.3 & 9 \mathrm{H} & 108.2 & 0.8 \\ 5 & 2.5 & 95.3 & 9 \mathrm{H} & 105.9 & 0.7\end{array}$

${ }^{a}$ Conditions: PUA is PUA-4. The other conditions were the same as in Table 2.

various molar ratios of acrylate to mercaptopropyl is shown in Figure 2, which exhibits that the UV-cured materials obtained

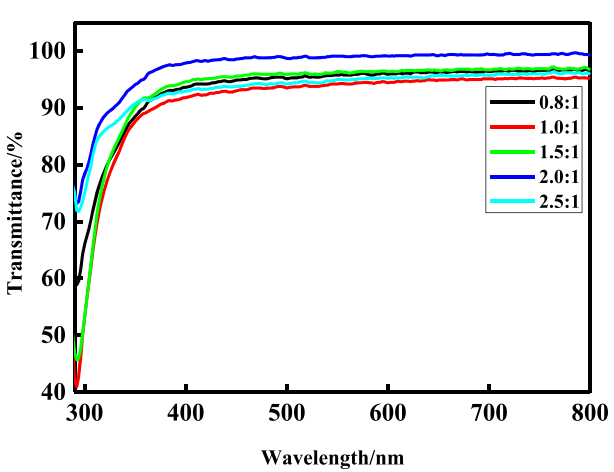

Figure 2. Transmittance of UV-cured materials prepared with various molar ratios of acrylate to mercaptopropyl.

have an outstanding transmittance higher than $92.0 \%$ within the visible light of $400-800 \mathrm{~nm}$. Especially, when the molar ratio of acrylate to mercaptopropyl is $2.0: 1$, the UV-cured material exhibits the highest transmittance in the range of 95.0-99.5\% (400-800 nm). By comparison, the transmittance of UV-cured materials in this study is far higher than that of UV-cured polyether-modified polysiloxane PUA reported by Cheng et al. $(80 \%, 400-800 \mathrm{~nm}) .{ }^{17}$ These results indicate that the UV-cured materials may be suitable candidates for package or protecting optical devices.

2.2.2. Flexibility and Mechanical Performance. Elastomers for fabricating soft and stretchable optical and electronics devices primarily require high tensile strength and high elongation at break. ${ }^{3}$ Development of flexible silicone materials with both good mechanical performance and fairly high transmittance is still a challenge. ${ }^{3,5,10,13,16}$ Unexpectedly, it is found that the UV-cured materials peeled from glass slides demonstrate good flexibility because they do not break after being bent, twisted (shown by Figure 3), and stretched (shown by Video S1) repeatedly, which induce us to further study the tensile performance of the UV-cured materials obtained. It is observed from the stress-strain curves shown in Figure 4a that when the molar ratio of acrylate to mercaptopropyl increases from $0.8: 1$ to $2.0: 1$, the tensile strength and elongation at break of the materials increase from 0.73 to $3.40 \mathrm{MPa}$ and 167.0 to $249.0 \%$, respectively. A further increment of the molar ratio of acrylate to mercaptopropyl will lead to a decline of tensile strength and elongation at break, which may due to excessive cross-linking of UV-cured materials. 


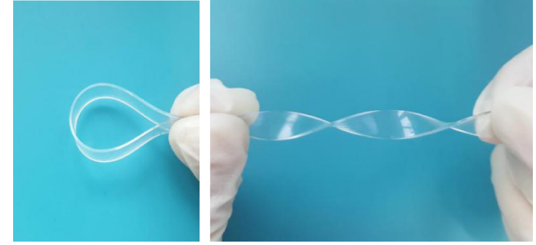

Figure 3. Photos for UV-cured materials (be bent and twisted) peeled from glass slides. (a) UV-cured materials prepared with various molar ratios of acrylate to mercaptopropyl. (b) UV-cured materials prepared with various PUAs prepared with different molar ratios of TMP to PTMG.
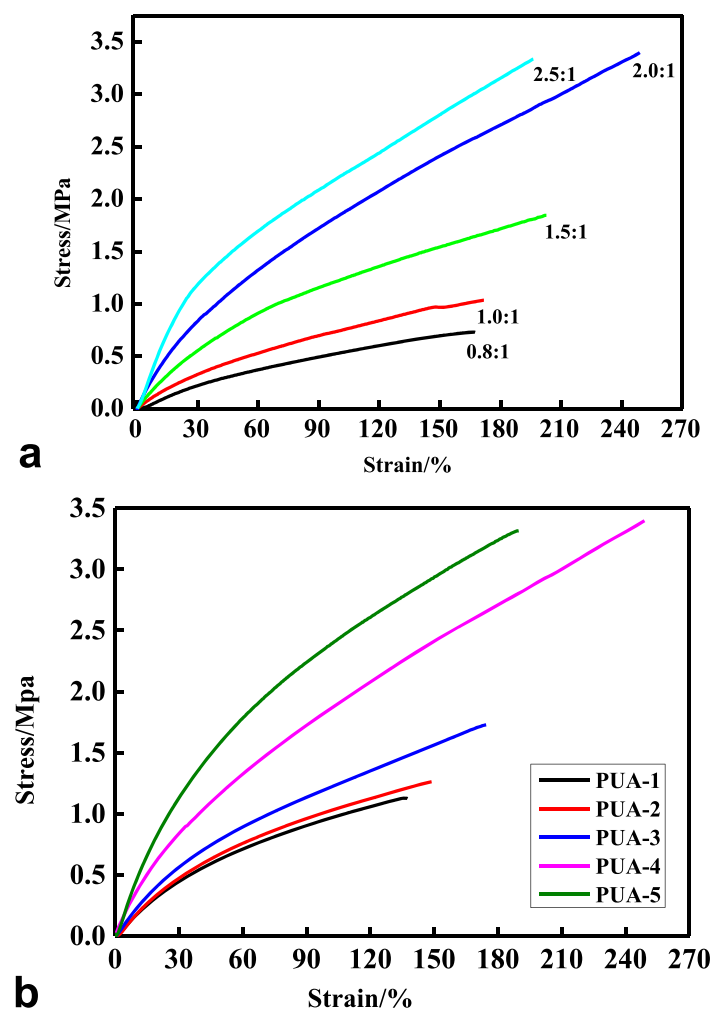

Figure 4. Stress-strain curves of UV-cured materials.

The mechanical performance of UV-cured materials also was affected by the PUAs prepared with various molar ratios of TMP to PTMG as shown in Figure 4b. It reveals that the tensile strength and elongation at break of the materials increase with the increasing molar ratio of TMP to PTMG in the range of 5:100-20:100. A further increment of molar ratio of TMP to PTMG will lead to a decreasing tensile strength and elongation at break, which may be due to the excessive crosslinking of UV-cured materials.

As reported previously, the tensile strength of unreinforced pure silicone materials with high transmittance is generally no more than $0.4 \mathrm{MPa}^{11,12}$ Also, as discussed above, though commercial silicone elastomers Sylgard 184, 186, and their blends have superior tensile strength, their tensile strength is still no more than $2.4 \mathrm{MPa}^{3,10}$ The tensile strength and elongation at break of UV-cured transparent silicone materials with sulfur-containing hyperbranched polycarbosilane and thiol silicone resin by our group are $2.2 \mathrm{MPa}$ and $21.4 \%$, respectively. ${ }^{13}$ On the basis of these results, it can be deduced that the UV-cured materials have outstanding flexibility and mechanical performance.
2.2.3. Thermal Stability. The thermal stability of the transparent materials for some optical or electronics devices is essential because the materials may endure a fairy high temperature due to the heat generated at the operation of these devices. ${ }^{42}$ However, the degradation temperature corresponding to $5 \%$ weight loss $\left(T_{\mathrm{d}} 5 \%\right)$ of conventional PUs is generally lower than $200{ }^{\circ} \mathrm{C} . .^{28,43,44}$ It can be seen from the TGA curves shown in Figure 5 that the $T_{\mathrm{d}} 5 \%$ of the materials obtained

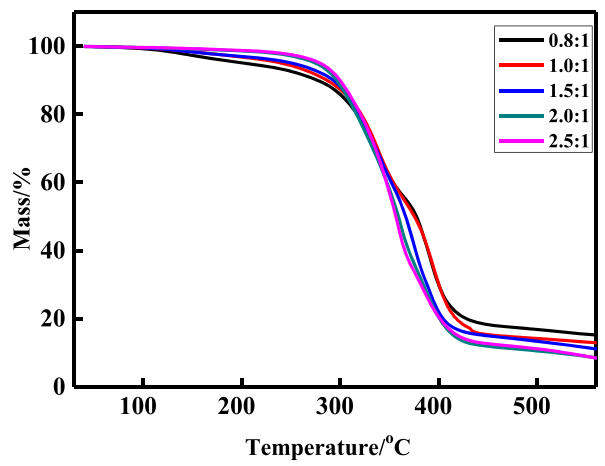

Figure 5. TGA curves of UV-cured materials prepared with various molar ratios of acrylate to mercaptopropyl.

increases from 203.4 to $281.0{ }^{\circ} \mathrm{C}$ when the molar ratio of acrylate to mercaptopropyl increases from $0.8: 1$ to $2.5: 1$, which is obviously higher than those of the conventional PUs reported. ${ }^{28,43,44}$

2.2.4. UV Resistance Property. As we know, the UV resistance property is quite important for optical materials, especially for the materials' application in optical devices exposed to UV or outdoor long term. To investigate the UV resistance property of UV-cured materials, the materials were aged in a UV test chamber of $10.6 \mathrm{~mW} \mathrm{~cm}^{-2}$ for various times (Figure 6). According to Figure 6, yellowing increases step by

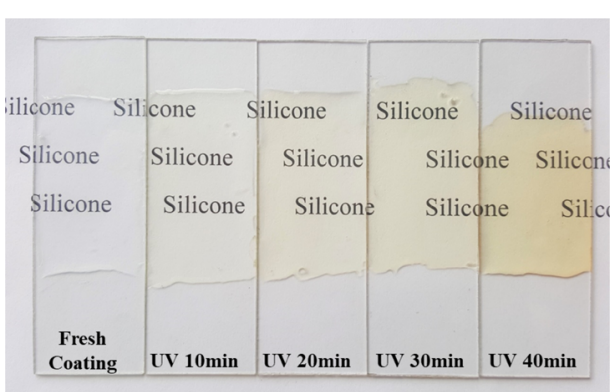

Figure 6. Photos for UV resistance measurement of a UV-cured material (sample 4 in Table 3) aged in a UV test chamber of $10.6 \mathrm{~mW}$ $\mathrm{cm}^{-2}$.

step with increasing irradiation time in the UV chamber. The UV-cured material turns slightly yellow when it is aged for about $10 \mathrm{~min}$. However, the transmittance of the material is still as high as $93.4 \%(800 \mathrm{~nm})$ after being exposed to $\mathrm{UV}$ for $40 \mathrm{~min}$ (Figure 7). It can be confirmed that the UV-cured material has fairly good UV resistance properties.

2.2.5. Adhesion Property. Good adhesion between the packaging or protecting materials and the substrates of optical or electronics devices is an essential requirement, ${ }^{5,28,36}$ which is assessed by a cross-cut test as shown by Figure 8 and Table 4. When the molar ratio of acrylate to mercaptopropyl is $2.0: 1$, the UV-cured materials exhibit the best adhesion to substrates 


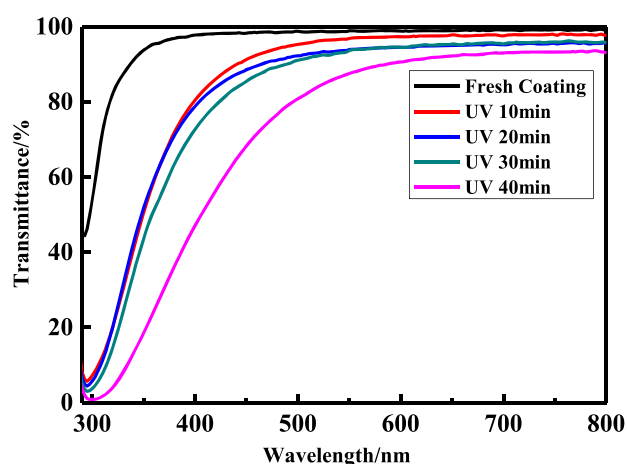

Figure 7. Transmittance for a UV-cured material (sample 4 in Table 3) before and after UV resistance measurement.

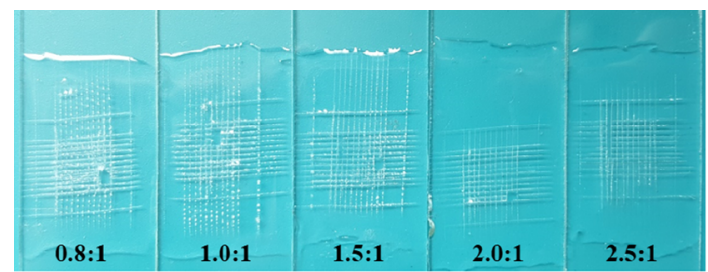

(a)

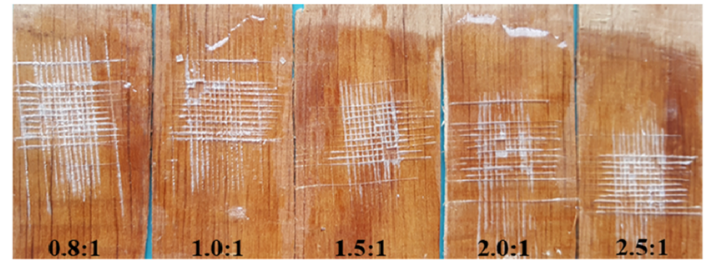

(b)

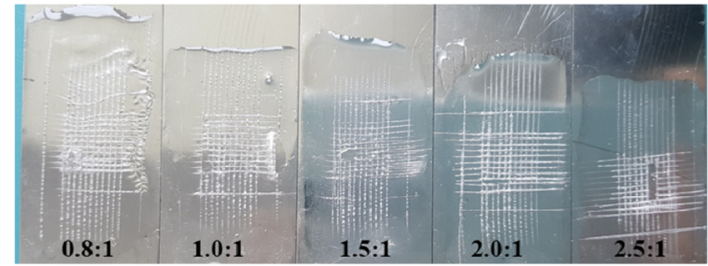

(c)

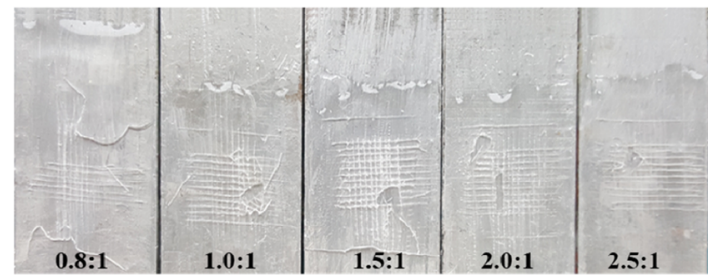

(d)

Figure 8. Photos for the adhesive experiments of the coatings on various substrates. (a) On glass slides. (b) On wood. (c) On tin plates. (d) On aluminum plates.

and the adhesion to a glass slide, wood, and a tin plate is grade 1 , while the adhesion to an aluminum plate is relatively poor and is of grade 2. It denotes that the UV-cured materials possess a fairly good adhesion property to a glass slide, wood, and a tin plate.

2.3. Application in a Self-Adsorption Gel Box. The Gel-Pak product is designed to protect and store sensitive and valuable devices and samples such as semiconductor devices, sensors, micromechanical devices, optical materials, and biomedical devices during transportation, processing, inspec- tion, and assembly. To assess the potential utility of the UVcured transparent silicone materials in the Gel-Pak product, the hyperbranched silicone polymers containing mercaptopropyl substitutes and PUA-4 were mixed according to the molar ratio of acrylate to mercaptopropyl of $2.0: 1$ and the mixtures were degassed in vacuum and then poured into a Gel-Pak box. The UV-curable system in a Gel-Pak box was cured for $50 \mathrm{~s}$ and then two transparent samples were put onto the Gel-Pak product shown in Figure 9. It is illustrated by Figure 9 that the sensitive and valuable devices are loaded and automatically adsorbed on the surface of the UV-cured material even when the box was placed vertically. It can be concluded that the UVcured materials may be one of the good candidates for use as packaging or protecting materials of optical or electronics devices such as a Gel-Pak product.

\section{EXPERIMENTAL SECTION}

3.1. Materials. PTMG $\left(M_{n}=2000, A R\right)$, poly propylene glycol $\left(M_{\mathrm{n}}=1000, \mathrm{AR}\right)$, neopentyl glycol (NPG, AR), isophorone diisocyanate (AR), ditin butyl dilaurate (AR), TMP (AR), hydroxypropyl acrylate (AR), and 3-trimethoxysilylpropanethiol (AR) were purchased from Beijing HWRK Chem. Co., Ltd. Various PUAs were synthesized by varying the mole ratio of the raw materials according to the work reported by our group as shown in Table $S 1 .{ }^{28}$

3.2. Synthesis of Hyperbranched Silicon-Containing Polymers Containing Mercaptopropyl Substitutes. A hyperbranched silicone-containing polymer with mercaptopropyl substitutes (HBPSH) was synthesized according to Scheme $1 .^{45,46} 17.706 \mathrm{~g}$ of NPG $(0.17 \mathrm{~mol})$ and $19.634 \mathrm{~g}$ of 3 trimethoxysilylpropanethiol $(0.1 \mathrm{~mol})$ were added into a 50 $\mathrm{mL}$ four-necked flask equipped with a thermometer, a top stirrer, a $\mathrm{N}_{2}$ gas inlet, and a distilling setup at room temperature. Then, the mixture was heated and kept at around $100{ }^{\circ} \mathrm{C}$ until some distillate was distilled off. Then, the mixture was heated to about $160{ }^{\circ} \mathrm{C}$ and the distillate kept at a temperature below $78{ }^{\circ} \mathrm{C}$ until the distillate temperature dropped below $55{ }^{\circ} \mathrm{C}$. Subsequently, the residual small molecules were taken off under $110{ }^{\circ} \mathrm{C} / 30 \mathrm{mmHg}$ and a transparent liquid with good fluidity of a hyperbranched silicone-containing polymer bearing mercaptopropyl and hydroxyl groups, recorded as HBPSH, was prepared. The ${ }^{1} \mathrm{H}$ NMR, ${ }^{29}$ Si NMR, FT-IR spectrum, and SEC curve are shown in Figures $\mathrm{S} 1-\mathrm{S} 4$, respectively.

${ }^{1} \mathrm{H}$ NMR spectrum (400 Hz, shown in Figure S1): 3.86$3.80,3.78-3.45$, and $3.37 \mathrm{ppm}$ correspond to $-\mathrm{SiOCH}_{2} \mathrm{C}$ $\left(\mathrm{CH}_{3}\right)_{2} \mathrm{CH}_{2} \mathrm{OSi}-\& \mathrm{HOCH}_{2} \mathrm{C}\left(\mathrm{CH}_{3}\right)_{2} \mathrm{CH}_{2} \mathrm{OSi}-, \mathrm{HOCH}_{2} \mathrm{C}-$ $\left(\mathrm{CH}_{3}\right)_{2} \mathrm{CH}_{2} \mathrm{O}-,-\mathrm{SiOCH}_{3}$, respectively. $1.85-1.64$ and 1.40$1.23 \mathrm{ppm}$ are assigned to $-\mathrm{SiCH}_{2} \mathrm{CH}_{2} \mathrm{CH}_{2} \mathrm{SH}$ and $-\mathrm{SiCH}_{2} \mathrm{CH}_{2} \mathrm{CH}_{2} \mathrm{SH}$, respectively. $1.10-0.97 \mathrm{ppm}$ are assigned to $-\mathrm{SiOCH}_{2} \mathrm{C}\left(\mathrm{CH}_{3}\right)_{2} \mathrm{CH}_{2} \mathrm{OSi}-\& \mathrm{HOCH}_{2} \mathrm{C}$ $\left(\mathrm{CH}_{3}\right)_{2} \mathrm{CH}_{2} \mathrm{OSi}-$. 2.60-2.48 and 1.05-0.66 ppm are assigned to $-\mathrm{SiCH}_{2} \mathrm{CH}_{2} \mathrm{CH}_{2} \mathrm{SH}$ and $-\mathrm{SiCH}_{2} \mathrm{CH}_{2} \mathrm{CH}_{2} \mathrm{SH}$, respectively.

${ }^{29} \mathrm{Si}$ NMR spectroscopy was employed to characterize the HBPSH obtained as shown in Figure S2. It can be seen that the HBPSH mainly has two different chemical shifts at -44.56 and $-45.02 \mathrm{ppm}$, respectively, attributed to the complete branched and the incomplete branched $\mathrm{Si}$, which is according to ref 46.

It can be revealed by the FT-IR spectrum in Figure S3 that the characteristic peaks at 3343,2570 , and $1057 \mathrm{~cm}^{-1}$ can be ascribed to residual $-\mathrm{OH}$ groups, mercaptopropyl groups, and $\mathrm{Si}-\mathrm{O}-\mathrm{C}$ bonds, respectively. It can be found that the $-\mathrm{OH}$ 
Table 4. Adhesive Properties of the Coatings on Various Substrates ${ }^{a}$

\begin{tabular}{|c|c|c|c|c|c|c|c|c|}
\hline \multirow[b]{2}{*}{ molar ratio of acrylate to mercaptopropyl } & \multicolumn{2}{|c|}{ glass slides } & \multicolumn{2}{|c|}{ wood } & \multicolumn{2}{|c|}{ tin plates } & \multicolumn{2}{|c|}{ aluminum plates } \\
\hline & $\mathrm{DR} / \%$ & grade & $\mathrm{DR} / \%$ & grade & $\mathrm{DR} / \%$ & grade & $\mathrm{DR} / \%$ & grade \\
\hline $0.8: 1$ & 12 & 2 & 11 & 2 & 15 & 2 & 47 & 4 \\
\hline $1.0: 1$ & 10 & 2 & 10 & 2 & 8 & 2 & 22 & 3 \\
\hline $1.5: 1$ & 10 & 2 & 7 & 2 & 7 & 2 & 20 & 3 \\
\hline $2.0: 1$ & 4 & 1 & 4 & 1 & 5 & 1 & 11 & 2 \\
\hline $2.5: 1$ & 7 & 2 & 7 & 2 & 14 & 2 & 14 & 2 \\
\hline
\end{tabular}

${ }^{a} \mathrm{DR}$ : means detachment ratio.

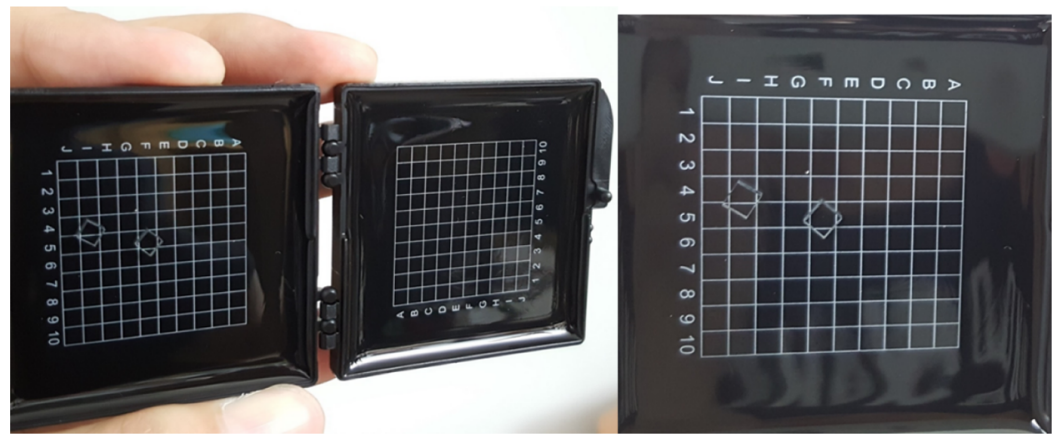

Figure 9. Photos for the Gel-Pak product prepared by a UV-cured material. Conditions: the conditions are the same as in sample 4 in Table 3.

\section{Scheme 1. Synthesis Route for HBPSH}

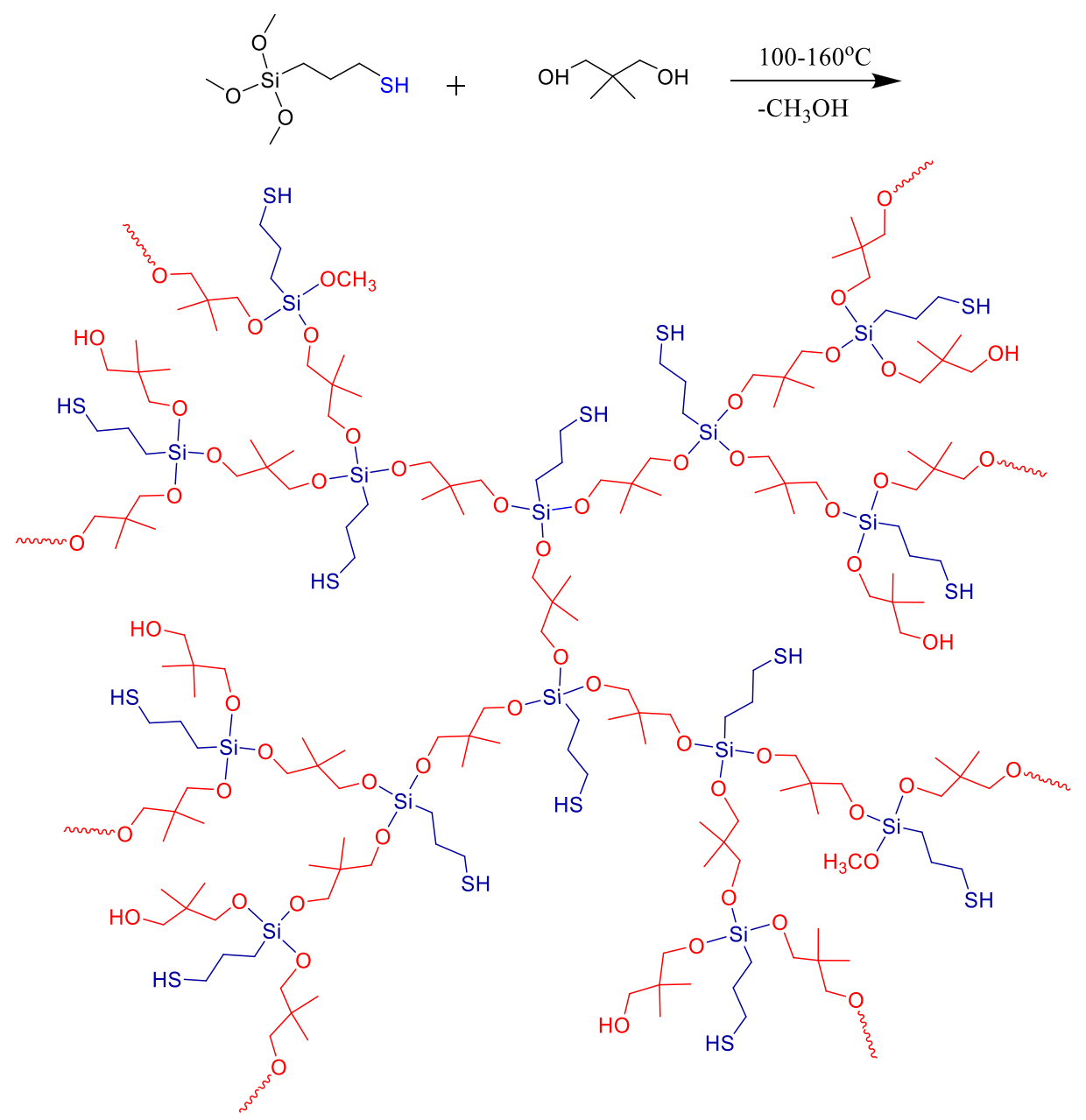


group appears to have a much weaker absorption due to the reaction of a large number of $-\mathrm{OH}$ groups with $-\mathrm{OCH}_{3}$ groups in 3-trimethoxysilylpropanethiol. ${ }^{45,46}$

Figure S4 reveals that the HBPSH prepared is with an average number average molecular weight $\left(M_{n}\right)$ of about 2.90 $\times 10^{3}$. It should be pointed that the $\alpha$ constant of MarkHouwink-Sakurada is $0.282( \pm 0.072 \%)$, which proves that the HBPSH prepared is a kind of HBP.

3.3. Preparation of UV-Cured Materials. The UV-cured materials were prepared according to Scheme 2 similar to refs

\section{Scheme 2. Preparation of UV-Cured Materials}

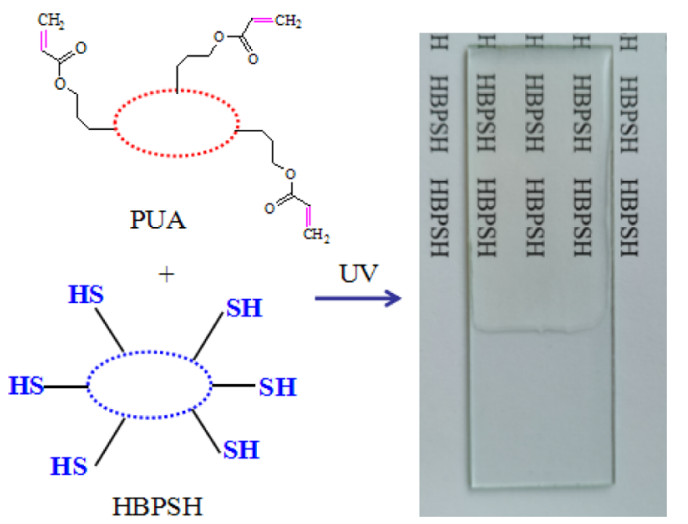

47 and 48 . As a typical procedure, about $0.4 \mathrm{~g}$ of homogeneous mixtures of HBPSH and PUAs was deposited on about half of the glass slides and kept away from light for $24 \mathrm{~h}$ under ambient temperature to let the coatings be as smooth as possible; then, the coatings with a thickness of about $0.5 \mathrm{~mm}$ were cured by UV (ZB1000, Changzhou Zibo Electron Technology Co., Ltd., laser wavelength $365 \mathrm{~nm}$, radiation intensity $10.6 \mathrm{~mW} \mathrm{~cm}^{-2}$, the distance of the slides to the light is $20 \mathrm{~cm}$ ). Specially, if the UV-cured materials were prepared to be flexible transparent silicone films peeled off from glass slides, about $1.6 \mathrm{~g}$ homogeneous mixtures of $\mathrm{HBPSH}$ and PUAs were deposited on the total of the glass slides and kept away from light for $24 \mathrm{~h}$ at ambient temperature; then, the coatings with a thickness of about $0.7 \mathrm{~mm}$ were cured by UV before the films were peeled from the glass slides.

3.4. Characterization. ${ }^{1} \mathrm{H}$ NMR and ${ }^{29} \mathrm{Si}-\mathrm{NMR}$ spectra were recorded on a Bruker AVANCE AV400 (400 MHz) spectrometer and a Bruker AVANCE AV600 (600 MHz) spectrometer, respectively, in $\mathrm{CDCl}_{3}$ without tetramethylsilane as the internal reference in a quartz NMR tube. FT-IR spectroscopic analysis of coatings scraped from the glass slides was performed on a Nicolet 700 spectrometer (Nicolet Co., Ltd., USA). Thermal properties of the coatings were examined by a thermogravimetric analyzer (TG 209C, Netzsch, German) in which samples were heated from ambient temperature to $550{ }^{\circ} \mathrm{C}$ at a rate of $10^{\circ} \mathrm{C}$ min $^{-1}$ in an $\mathrm{N}_{2}$ atmosphere. The SEC curve of HBPSH was recorded on a Waters 1515 (USA) with tetrahydrofuran as the fluent. The tensile test of the films (6 $\mathrm{mm} \times 0.7 \mathrm{~mm} \times 8 \mathrm{~mm}$ strips) scraped from the slides was carried out according to GB/T 528-2009/ISO 37:2005 on an UH6503D electronic tensile testing machine (Optimal Hung Measurement \& Control Technology (Shanghai) Co. Ltd). The load is $100 \mathrm{~N}$ at a loading rate of $60 \mathrm{~mm} / \mathrm{min}$. Transmittance, pencil hardness, degree of curing contents, and adhesion property were measured according to refs. ${ }^{13,28,47}$ UV resistance measurement of the UV-cured material was conducted in a UV test chamber of $10.6 \mathrm{~mW} \mathrm{~cm}^{-2}$. The crosslinking density of UV-cured materials was evaluated by a swelling experiment similar to the reference shown in Table S3. ${ }^{39}$ The higher the SD, the lower the cross-linking density of UV-cured materials will be. The samples were immersed in toluene for $72 \mathrm{~h}$ and SD expressed as SD $=\left[m_{0} / \rho_{\mathrm{e}}+(m-\right.$ $\left.\left.m_{0}\right) / \rho_{\mathrm{s}}\right] /\left(m_{0} / \rho_{\mathrm{e}}\right)$, where $m_{0}$ and $m$ refer to the masses of the unswollen and swollen material (in $\mathrm{g}$ ), respectively, and $\rho_{\mathrm{e}}$ and $\rho_{\mathrm{s}}$ refer to the density of the UV-cured material and toluene (in $\mathrm{g} \mathrm{cm}^{-3}$ ), respectively. The density of the UV-cured material was measured by the drainage method.

\section{CONCLUSIONS}

In this work, it was demonstrated that UV-cured flexible transparent silicone materials for optical and electronic devices could be fabricated by HBPSHs and PUAs. Unexpectedly, it is found that the film of the UV-cured materials demonstrates extraordinary flexibility because it did not break after being bent, twisted, and stretched repeatedly. Compared to the silicone materials with high transmittance, it is found that both the tensile strength and elongation at break of the transparent silicone materials are extraordinarily high, which can reach 3.40 $\mathrm{MPa}$ and $270.0 \%$, respectively. The pencil hardness of the cured materials is in the range of $2 \mathrm{~B}-9 \mathrm{H}$, transmittance could reach $95.0-99.5 \%(400-800 \mathrm{~nm})$, and the starting decomposition temperature is about $203.4-281.0^{\circ} \mathrm{C}$. Yellowing of the materials increases step by step with increasing irradiation time in the UV chamber of $10.6 \mathrm{~mW} \mathrm{~cm}^{-2}$, and the transmittance of the materials is still as high as $93.4 \%$ (800 $\mathrm{nm}$ ) even though they were aged for $40 \mathrm{~min}$. They exhibit outstanding adhesion to substrates, and the adhesion to a glass slide, wood, and a tin plate is grade 1 . An attempt was made to apply the UV-cured materials in the Gel-Pak box and it could be proved that the UV-cured materials may be one of the good candidates for use as packaging or protecting materials of optical or electronics devices such as the Gel-Pak product. The promising results of this work can encourage scientists to further improve the mechanical performance of flexible transparent silicone materials by effective chemical modification strategies with HBPs and expand the application of flexible transparent silicone materials in optical and electronic devices.

\section{ASSOCIATED CONTENT}

\section{sI Supporting Information}

The Supporting Information is available free of charge at https://pubs.acs.org/doi/10.1021/acsomega.0c05243.

Feed ratios and scheme for the preparation of PUAs; ${ }^{1} \mathrm{H}$ NMR, ${ }^{29} \mathrm{Si}$ NMR, FT-IR, and SEC characterization of HBPSH; SD of UV-cured materials with various PUAs; and contact angle for the coatings of cured materials prepared with various molar ratios of acrylate to mercaptopropyl (PDF)

The stretched repeatedly video for the film peeled from glass slide (MP4)

\section{AUTHOR INFORMATION}

\section{Corresponding Authors}

Guoqiao Lai - Key Laboratory of Organosilicon Chemistry and Material Technology of Education Ministry, College of Material, Chemistry, and Chemical Engineering, Hangzhou Normal University, Hangzhou 311121, China;

Email: gqlai@hznu.edu.cn 
Xiongfa Yang - Key Laboratory of Organosilicon Chemistry and Material Technology of Education Ministry, College of Material, Chemistry, and Chemical Engineering, Hangzhou Normal University, Hangzhou 311121, China; 이이.org/ 0000-0002-8688-0162; Email: yangxiongfa@hznu.edu.cn

\section{Authors}

Xiaojiao Jiao - Key Laboratory of Organosilicon Chemistry and Material Technology of Education Ministry, College of Material, Chemistry, and Chemical Engineering, Hangzhou Normal University, Hangzhou 311121, China

Jiangling Liu - Key Laboratory of Organosilicon Chemistry and Material Technology of Education Ministry, College of Material, Chemistry, and Chemical Engineering, Hangzhou Normal University, Hangzhou 311121, China

Jing Jin - Taizhou Vocational College of Science \& Technology, Taizhou 318020, China

Fei Cheng - Key Laboratory of Organosilicon Chemistry and Material Technology of Education Ministry, College of Material, Chemistry, and Chemical Engineering, Hangzhou Normal University, Hangzhou 311121, China

Yunxin Fan - Key Laboratory of Organosilicon Chemistry and Material Technology of Education Ministry, College of Material, Chemistry, and Chemical Engineering, Hangzhou Normal University, Hangzhou 311121, China

Lu Zhang - Key Laboratory of Organosilicon Chemistry and Material Technology of Education Ministry, College of Material, Chemistry, and Chemical Engineering, Hangzhou Normal University, Hangzhou 311121, China

Xilin Hua - Key Laboratory of Organosilicon Chemistry and Material Technology of Education Ministry, College of Material, Chemistry, and Chemical Engineering, Hangzhou Normal University, Hangzhou 311121, China

Complete contact information is available at:

https://pubs.acs.org/10.1021/acsomega.0c05243

\section{Notes}

The authors declare no competing financial interest.

\section{ACKNOWLEDGMENTS}

The authors are grateful for financial support from the Open Fund of the Collaborative Innovation Centre for Fluorosilicon Fine Chemicals and Materials Manufacturing of Zhejiang Province (FSi2019A007) and Hangzhou Hanghua Ink Co. Ltd.

\section{REFERENCES}

(1) Dogbevi, K. S.; Ngo, B. K. D.; Blake, C. W.; Grunlan, M. A.; Coté, G. L. Pumpless, "Self-Driven" Microfluidic Channels with Controlled Blood Flow Using an Amphiphilic Silicone. ACS Appl. Polym. Mater. 2020, 2, 1731-1738.

(2) Portnoi, M.; Macdonald, T. J.; Sol, C.; Robbins, T. S.; Li, T.; Schläfer, J.; Guldin, S.; Parkin, I. P.; Papakonstantinou, I. All-Siliconebased Distributed Bragg Reflectors for Efficient Flexible Luminescent Solar Concentrators. Nano Energy 2020, 70, 104507.

(3) Vaicekauskaite, J.; Mazurek, P.; Vudayagiri, S.; Skov, A. L. Mapping the Mechanical and Electrical Properties of Commercial Silicone Elastomer Formulations for Stretchable Transducers. J. Mater. Chem. C 2020, 8, 1273-1279.

(4) Miao, J.-T.; Yuan, L.; Guan, Q.; Liang, G.; Gu, A. Water-Phase Synthesis of a Biobased Allyl Compound for Building UV-Curable Flexible Thiol-Ene Polymer Networks with High Mechanical Strength and Transparency. ACS Sustainable Chem. Eng. 2018, 6, 7902-7909.
(5) Yang, X.; Shao, Q.; Yang, L.; Zhu, X.; Hua, X.; Zheng, Q.; Song, G.; Lai, G. Preparation and Performance of High Refractive Index Silicone Resin-Type Materials for the Packaging of Light-Emitting Diodes. J. Appl. Polym. Sci. 2013, 127, 1717-1724.

(6) Yang, X.; Liu, J.; Wu, Y.; Liu, J.; Cheng, F.; Jiao, X.; Lai, G. Fabrication of UV-Curable Solvent-Free Epoxy Modified Silicone Resin Coating with High Transparency and Low Volume Shrinkage. Prog. Org. Coat. 2019, 129, 96-100.

(7) Deng, X.-R.; Yang, W.; Zhang, Q.-H.; Hui, H.-H.; Wei, Y.-W.; Wang, J.; Xu, Q.; Lei, X.-Y.; Chen, J.-J.; Zhu, J.-L. Fabrication of UVCurable Silicone Coating with High Transmittance and LaserInduced Damage Threshold for High-Power Laser System. J. SolGel Sci. Technol. 2018, 88, 249-254.

(8) Rao, Y.-L.; Chortos, A.; Pfattner, R.; Lissel, F.; Chiu, Y.-C.; Feig, V.; Xu, J.; Kurosawa, T.; Gu, X.; Wang, C.; He, M.; Chung, J. W.; Bao, Z. Stretchable Self-Healing Polymeric Dielectrics Cross-Linked Through Metal-Ligand Coordination. J. Am. Chem. Soc. 2016, 138, 6020-6027.

(9) Yang, X.-F.; Liu, J.; Chen, Q.; Shen, Y.-P.; Liu, H.-Z.; Lai, G.-Q. A Low Temperature Vulcanized Transparent Silane Modified Epoxy Resins for LED Filament Bulb Package. Chin. J. Polym. Sci. 2018, 36, 649-654.

(10) Park, S.; Mondal, K.; Treadway, R. M., III; Kumar, V.; Ma, S.; Holbery, J. D.; Dickey, M. D. Silicones for Stretchable and Durable Soft Devices: Beyond Sylgard-184. ACS Appl. Mater. Interfaces 2018, 10, 11261-11268.

(11) Sun, Z.; Huang, Q.; Wang, Y.; Zhang, L.; Wu, Y. Structure and Properties of Silicone Rubber/Styrene-Butadiene Rubber Blends with in Situ Interface Coupling by Thiol-ene Click Reaction. Ind. Eng. Chem. Res. 2017, 56, 1471-1477.

(12) Li, Q.; Huang, X.; Liu, H.; Shang, S.; Song, Z.; Song, J. Preparation and Properties of Room Temperature Vulcanized Silicone Rubber Based on Rosin-Grafted Polydimethylsiloxane. RSC Adv. 2018, 8, 14684-14693.

(13) Wu, Y.; Liu, J.; Jiao, X.; Cheng, F.; Lai, G.; Yang, X. UV-Cured Transparent Flexible Silicone Materials with High Tensile Strength. ACS Omega 2020, 5, 6199-6206.

(14) Yan, F.; Zhang, X.; Liu, F.; Li, X.; Zhang, Z. Adjusting the properties of silicone rubber filled with nanosilica by changing the surface organic groups of nanosilica. Composites, Part B 2015, 75, 4752.

(15) Heidarian, J.; Hassan, A. Microstructural and Thermal Properties of Fluoroelastomer/Carbon Nanotube Composites. Composites, Part B 2014, 58, 166-174.

(16) Liao, Y.-T.; Lin, Y.-C.; Kuo, S.-W. Highly Thermally Stable, Transparent, and Flexible Polybenzoxazine Nanocomposites by Combination of Double-Decker-Shaped Polyhedral Silsesquioxanes and Polydimethylsiloxane. Macromolecules 2017, 50, 5739-5747.

(17) Cheng, J.; Li, M.; Cao, Y.; Gao, Y.; Liu, J.; Sun, F. Synthesis and Properties of Photopolymerizable Bifunctional Polyether-Modified Polysiloxane Polyurethane Acrylate Prepolymer. J. Adhes. Sci. Technol. 2016, 30, 2-12.

(18) Chen, X.; Zhang, G.; Zhang, Q.; Zhan, X.; Chen, F. Preparation and Performance of Amphiphilic Polyurethane Copolymers with Capsaicin-Mimic and PEG Moieties for Protein Resistance and Antibacteria. Ind. Eng. Chem. Res. 2015, 54, 3813-3820.

(19) Zhang, W.; Zhang, Y.; Liang, H.; Liang, D.; Cao, H.; Liu, C.; Qian, Y.; Lu, Q.; Zhang, C. High Bio-Content Castor Oil Based Waterborne Polyurethane/Sodium Lignosulfonate Composites for Environmental Friendly UV Absorption Application. Ind. Crops Prod. 2019, 142, 111836

(20) Dash, K.; Hota, N. K.; Sahoo, B. P. Fabrication of thermoplastic polyurethane and polyaniline conductive blend with improved mechanical, thermal and excellent dielectric properties: exploring the effect of ultralow-level loading of SWCNT and temperature. $J$. Mater. Sci. 2020, 55, 12568-12591.

(21) Peng, C.; Huang, S.; You, Z.; Xu, F.; You, L.; Ouyang, H.; Li, T.; Guo, C.; Ma, H.; Chen, P.; Dai, J. Effect of a Lignin-Based 
Polyurethane on Adhesion Properties of Asphalt Binder During UV Aging Process. Constr. Build. Mater. 2020, 247, 118547.

(22) Chun, Y.-C.; Kim, K.-S.; Shin, J.-S.; Kim, K.-H. Synthesis and Characterization of Poly(Siloxane-Urethane)s. Polym. Int. 1992, 27, $177-185$.

(23) Kozakiewicz, J. Polysiloxaneurethanes: New Polymers for Potential Coating Applications. Prog. Org. Coat. 1996, 27, 123-131.

(24) Xu, Y.; Luo, J.; Liu, X.; Liu, R. Polyurethane modified epoxy acrylate resins containing $\varepsilon$-caprolactone unit. Prog. Org. Coat. 2020, 141, 105543.

(25) Liu, J.; Zhou, Z.; Su, X.; Cao, J.; Chen, M.; Liu, R. Stiff UVCurable Self-Healing Coating Based on Double Reversible Networks Containing Diels-Alder Cross-Linking and Hydrogen Bonds. Prog. Org. Coat. 2020, 146, 105699.

(26) Zhang, H.; Xue, L.; Li, J.; Ma, Q. Hyperbranched Polycarbosiloxanes: Synthesis by Piers-Rubinsztajn Reaction and Application as Precursors to Magnetoceramics. Polymers 2020, 12, 672.

(27) Xiang, H. P.; Rong, M. Z.; Zhang, M. Q. A Facile Method for Imparting Sunlight Driven Catalyst-Free Self-Healability and Recyclability to Commercial Silicone Elastomer. Polymer 2017, 108, 339.

(28) Liu, J.; Jiao, X.; Cheng, F.; Fan, Y.; Wu, Y.; Yang, X. Fabrication and Performance of UV Cured Transparent Silicone Modified Polyurethane-Acrylate Coatings with High Hardness, Good Thermal Stability and Adhesion. Prog. Org. Coat. 2020, 144, 105673.

(29) Ren, Y.; Dong, Y.; Zhu, Y.; Xu, J.; Yao, Y. Preparation, Characterization, and Properties of Novel Ultraviolet-Curable and Flame-Retardant Polyurethane Acrylate. Prog. Org. Coat. 2019, 129, 309-317.

(30) Malucelli, G.; Barbalini, M. UV-Curable Acrylic Coatings Containing Biomacromolecules: A New Fire Retardant Strategy for Ethylene-Vinyl Acetate Copolymers. Prog. Org. Coat. 2019, 127, 330-337.

(31) Liang, B.; Kuang, S.; Huang, J.; Man, L.; Yang, Z.; Yuan, T. Synthesis and Characterization of Novel Renewable Tung Oil-Based UV Curable Active Monomers and Bio-Based Copolymers. Prog. Org. Coat. 2019, 129, 116-124.

(32) Su, Y.; Lin, H.; Zhang, S.; Yang, Z.; Yuan, T. One-Step Synthesis of Novel Renewable Vegetable Oil-Based Acrylate Prepolymers and Their Application in UV-Curable Coatings. Polymers 2020, 12, 1165.

(33) Fu, J.; Yu, H.; Wang, L.; Lin, L.; Khan, R. U. Preparation and Properties of UV-Curable Hyperbranched Polyurethane Acrylate Hard Coatings. Prog. Org. Coat. 2020, 144, 105635.

(34) Kim, S.; Lee, J.; Han, H. Synthesis of UV Curable, Highly Stretchable, Transparent Poly(urethane-acrylate) Elastomer and Applications Toward Next Generation Technology. Macromol. Res. 2020, 28, 896-902.

(35) Li, L.; Liang, R.; Li, Y.; Liu, H.; Feng, S. Hybrid thiol-ene network nanocomposites based on multi(meth)acrylate POSS. J. Colloid Interface Sci. 2013, 406, 30-36.

(36) Magnoni, F.; Rannée, A.; Marasinghe, L.; El-Fouhaili, B.; Allonas, X.; Croutxé-Barghorn, C. Correlation Between the Scratch Resistance of UV-Cured PUA-Based Coatings and the Structure and Functionality of Reactive Diluents. Prog. Org. Coat. 2018, 124, 193199.

(37) Caro, J.; Cuadrado, N.; González, I.; Casellas, D.; Prado, J. M.; Vilajoana, A.; Artús, P.; Peris, S.; Carrilero, A.; Dürsteler, J. C. Microscratch Resistance of Ophthalmic Coatings on Organic Lenses. Surf. Coat. Technol. 2011, 205, 5040-5052.

(38) Lange, J.; Luisier, A. Influence of Crosslink Density, Glass Transition Temperature and Addition of Pigment and Wax on the Scratch Resistance of an Epoxy Coating. J. Coat. Technol. Res. 1997, $69,77-82$.

(39) Schweitzer, J.; Merad, S.; Schrodj, G.; Gall, F. B.-L.; Vonna, L. Determination of the Crosslinking Density of a Silicone Elastomer. J. Chem. Educ. 2019, 96, 1472-1478.

(40) Dai, J.; Liu, X.; Ma, S.; Wang, J.; Shen, X.; You, S.; Zhu, J. Soybean oil-based UV-curable coatings strengthened by crosslink agent derived from itaconic acid together with 2-hydroxyethyl methacrylate phosphate. Prog. Org. Coat. 2016, 97, 210-215.

(41) Favache, A.; Daniel, A.; Teillet, A.; Pardoen, T. Performance Indices and Selection of Thin Hard Coatings on Soft Substrates for Indentation and Scratch Resistance. Mater. Des. 2019, 176, 107827.

(42) Schneider, R.; Lüthi, S. R.; Albrecht, K.; Brülisauer, M.; Bernard, A.; Geiger, T. Transparent Silicone Calcium Fluoride Nanocomposite with Improved Thermal Conductivity. Macromol. Mater. Eng. 2015, 300, 80-85.

(43) Hui, B.; Ye, L. Highly Heat-Resistant Silicon-Containing Polyurethane-Imide Copolymers: Synthesis and Thermal Mechanical Stability. Eur. Polym. J. 2017, 91, 337-353.

(44) Pagacz, J.; Hebda, E.; Janowski, B.; Sternik, D.; Jancia, M.; Pielichowski, K. Thermal Decomposition Studies on Polyurethane Elastomers Reinforced with Polyhedral Silsesquioxanes by Evolved Gas Analysis. Polym. Degrad. Stab. 2018, 149, 129-142.

(45) Niu, S.; Yan, H.; Chen, Z.; Li, S.; Xu, P.; Zhi, X. Unanticipated Bright Blue Fluorescence Produced from Novel Hyperbranched Polysiloxanes Carrying Unconjugated Carbon-Carbon Double Bonds and Hydroxyl Groups. Polym. Chem. 2016, 7, 3747.

(46) Niu, S.; Yan, H.; Li, S.; Tang, C.; Chen, Z.; Zhi, X.; Xu, P. A Multifunctional Silicon-Containing Hyperbranched Epoxy: Controlled Synthesis, Toughening Bismaleimide and Fluorescent Properties. J. Mater. Chem. C 2016, 4, 6881-6893.

(47) Cheng, F.; Fan, Y.; Zhang, L.; Jiao, X.; Lai, G.; Hua, X.; Yang, $X$. An Easy Fabrication Method to Prepare Inexpensive UV-Cured Transparent Silicone Modified Polyacrylate Coatings with Good Adhesion and UV Resistance. Coatings 2020, 10, 675.

(48) Wu, Y.; Liu, J.; Cheng, F.; Jiao, X.; Fan, Y.; Lai, G.; Luo, M.; Yang, X. Fabrication of Transparent UV-Cured Coatings with AllylTerminated Hyperbranched Polycarbosilanes and Thiol Silicone Resins. ACS Omega 2020, 5, 15311-15316. 